\title{
CHARACTERIZATION OF SEVERAL WEST GEORGIAN AUTOCHTHONOUS GRAPES AND THEIR WINE STILBENES

\author{
Maia Kharadze $^{1}$, Maia Vanidze ${ }^{2}$, Indira Djaparidze ${ }^{3}$, Givi Kalandia ${ }^{4}$,
} Ruslan Davitadze ${ }^{5}$, Aleko Kalandia ${ }^{6}$
}

\begin{abstract}
The present study was conducted to determine the content of Stilbenes in the several autochthonous West Georgian grapes and wines. Stilbenes were analyzed using HPLC-UV samples and were prepared using resin (amberlite XAD2) column, C18 Cartridge Solid Phase Extraction (SPE) Waters Sep-Pak C18 (500 mg). The identification was achieved using UPLC-PDA and MS analysis. The study was conducted on the following Stilbenes and their derivatives - Astringin, Piceid, Trans/cis resveratrol, and $\varepsilon$-Viniferin. The amount of stilbenes in grapes was determined as: Aladasturi-131.9 $\pm 4.8 \mathrm{mg} \mathrm{kg}-1, \quad$ Aleksandrouli $\quad 148.2 \pm 4.9 \mathrm{mg} \mathrm{kg}-1, \quad$ Mujuretuli $215.3 \pm 7.9 \mathrm{mg} \mathrm{kg}-1$, Chkhaveri $77.5 \pm 2.5 \mathrm{mg} \mathrm{kg}-1$, Ojaleshi $260.71 \pm 9.1 \mathrm{mg} \mathrm{kg}-1$. In red wines the content of Stilbenes was Aladasturi-19.17 $\pm 0.5 \mathrm{mg} \mathrm{kg}-1$, Aleksandrouli 14. 87 $\pm 0.4 \mathrm{mg} \mathrm{kg}-1$, Mujuretuli 21.36 $\pm 0.5 \mathrm{mg}$ kg-1, Chkhaveri $14.5 \pm 0.4 \mathrm{mg} \mathrm{kg}-1$, Ojaleshi $60.8 \pm 2.2 \mathrm{mg} \mathrm{kg}-1$.

UDC Classification: 547.1, DOI: 10.12955/cbup.v7.1479
\end{abstract}

Keywords: stilbenes, red wines, HPLC-UV, UPLC-MS, PDA

\section{Introduction}

Stilbenes are non-flavonoid phenolic compounds present in plants (Shen et al., 2009). They are considered phytoalexins. They protect plants from many diseases and ultraviolet radiation (AlonsoVillaverde et al., 2011). The recent interest in them is explained by the fact that they are a powerful antioxidant with great activity (Gulcin, 2010; Marel et al., 2018; Hao et al., 2004). Against the backdrop of modern environmental problems, it is important that the human diet includes products with antioxidant properties. Such products can be grapes and wines, which contain various types of phenolic compounds (Rimando et al., 2004). The biological activity of phenolic compounds of the class of stilbenes, as physiologically active compounds, are tested in different directions (Wen et al., 2018). After the wine making process, the residues - the grape must (Anastasiadi et al., 2010; Tang et al., 2018), are often used for the production of dietary supplements. The research of Stilbenes is conducted by HPLC UV, MS, and PDA detection methods (Careri et al., 2003; Sánchez et al., 2005; Ji et al., 2014).

To prepare a sample, an extraction is carried out using different solvents and concentrates. The best option for extracting from grapes is alcohol mixed with water, and in the case of wine, it is a concentrated using Amberlite resin (Hurtado-Gaitán et al., 2017; López-Hernández et al., 2016; Decendit, 2017). The interest in studying stilbenes is great due to its antioxidant properties. Even though there are hundreds of autochronic grapes and wines in Georgia there is no prior research done on the determination of stilbene content in them. The goal of our project was to study stilbenes in some autochthonous West Georgian grapes and the wines made from them.

\section{Methods and materials}

High-performance liquid chromatography analysis was carried out on a Waters (Breeze, USA) HPLC system equipped with a model 1525 pump and UV detectors (2489). Separations were performed on a C18 column $(250 \times 4.6 \mathrm{~mm} ; 5 \mu \mathrm{m}$ particle size $)$ column temperature $30^{\circ} \mathrm{C}$. The mobile phases consisted of water $0.1 \%$ formic acid (solvent A) and acetonitrile $0.1 \%$ formic acid (solvent B). $200 \mu \mathrm{L}$ of each sample was injected and analyzed at $30{ }^{\circ} \mathrm{C}$. A elution program was performed at $2.7 \mathrm{mLmin}-{ }^{1}$ was $10 \%$ B (0-2 min), 10-60 \% B (2-14 min), $60 \%$ B (14-16 min) followed by a 2 min wash with $100 \% \mathrm{~B}$ and a 5 min re-equilibration step. at a flow rate of $1 \mathrm{~mL}_{-} \mathrm{min}^{-1}{ }^{1}$ The detection wavelengths were set at 290 and

\footnotetext{
${ }^{1}$ Batumi Shota Rustaveli State University, Faculty of Natural Sciences and Health Care, Department of Chemistry, Batumi, Georgia, maikharadze88@gmail.com

${ }^{2}$ Batumi Shota Rustaveli State University, Faculty of Natural Sciences and Health Care, Department of Chemistry, Batumi, Georgia, vanidzemaia@gmail.com

${ }^{3}$ Batumi Shota Rustaveli State University, Faculty of Natural Sciences and Health Care, Department of Chemistry, Batumi, Georgia, indira.djafaridze@gmail.com

${ }^{4}$ San Diego State University, Tbilisi, Georgia, givikalandia@gmail.com

${ }^{5}$ Batumi Shota Rustaveli State University, Faculty of Natural Sciences and Health Care, Department of Chemistry, Batumi, Georgia, davitadzer@gmail.com

${ }^{6}$ Batumi Shota Rustaveli State University, Faculty of Natural Sciences and Health Care, Department of Chemistry, Batumi, Georgia, aleko.kalandia@bsu.edu.ge
} 
$306 \mathrm{~nm}$. The elution program involved gradient elution from 35\% B for 3 min to reach 50\% B at 10 min, $70 \% \mathrm{~B}$ at $20 \mathrm{~min}$ and $100 \%$ at 23 to $28 \mathrm{~min}$. UPLC-PDA, MS, column BEN C18 (100x2.1 mm $1.7 \mu \mathrm{m})$. mobile phase $0.1 \%$ Formic acid in DW (A), $0.1 \%$ Formic acid in Acetonitrile (B), gradient solvent B $20 \% 13 \mathrm{~min}$, B $99 \%$ in $16 \mathrm{~min}$, B $1 \%$ in $18 \mathrm{~min}$, equilibrate 3 min. Flow 0,4 mlmin- ${ }^{1}$, column temp $40{ }^{\circ} \mathrm{C}$, MS- scan $40-1200 \mathrm{da}$, Probe $500{ }^{\circ} \mathrm{C}$, Positive $0,8 \mathrm{kV}$, Capillary 1,5 kV, CV -15, PDA scan $210-500 \mathrm{~nm}$. For identification and quantification purposes, standards of trans-resveratrol were used.

Wine samples were concentrated from 100 to $90 \mathrm{~mL}$ in a vacuum at a temperature of not more than $40^{\circ} \mathrm{C}$ (before alcohol removal). The concentrated wine was poured over Amberlite XAD-16 resin (SigmaAldrich), in an open column $(2.5 \mathrm{~cm}$ id $\times 14 \mathrm{~cm})$, and rinsed with $1 \mathrm{~L}$ of water to remove sugars, small organic acids and other non-polyphenol compounds. The polyphenols were then eluted with $1 \mathrm{~L}$ of methanol and $0.5 \mathrm{~L}$ of acetone. To prepare a sample of wine, it was concentrated from $100 \mathrm{~mL}$ to $10 \mathrm{~mL}$ a vacuum at no more than $400^{\circ} \mathrm{C}$. The resulting concentrate $(4 \mathrm{~mL})$ was subjected to column chromatography using Sep-pac C18 $500 \mathrm{mg}$ (SPE-Waters). The column was equilibrated with the mixtures of $4 \mathrm{~mL}$ methanol and $0.1 \%$ formic acid and $4 \mathrm{~mL}$ water and $0.1 \%$ formic acid, before injection of $5 \mathrm{~mL}$ samplers). Elution was performed with a mixture of water and $0.1 \%$ formic acid (chemical grade). Stilbenes extraction was performed with $4 \mathrm{~mL}$ of ethyl acetate. This fraction was concentrated and dissolved with a 90-10 ratio of A-B solvent $(0.5 \mathrm{~mL})$. All the samples were filtered

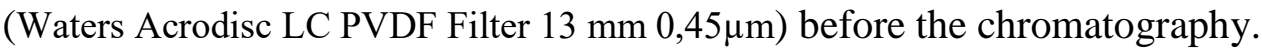

\section{Results and their review}

Using a HPLC preparation column, a chromatography was made of the obtained fractions UPLC- PDA, MS and the results were compared to the https://metlin.scripps.edu database as well as using literary data. It then became possible to identify the following compounds. A substance $1 \mathrm{~m} / \mathrm{z} 407,[\mathrm{M}-\mathrm{H}]+$, fragment $\mathrm{m} / \mathrm{z} 196[\mathrm{M}-\mathrm{H}]+\kappa \max 307$ according to the obtained results, the substance 1 is Astringin MW 406; a substance $2 \mathrm{~m} / \mathrm{z} 245$, [M-H] + , fragment m/z $135[\mathrm{M}-\mathrm{H}]+\kappa \max 306$ and,322 according to the obtained results a substance 2 is Piceatannol MW 244; a substance $3 \mathrm{~m} / \mathrm{z} 391$, [M-H]+, fragment $\mathrm{m} / \mathrm{z} 229[\mathrm{M}-\mathrm{H}]+K \max 308$ and 319 according to the obtained results a substance 3 is Piceid MW 390; a substance $4 \mathrm{~m} / \mathrm{z} 227$, [M-H]-], fragment m/z $107[\mathrm{M}-\mathrm{H}], \kappa \max 306$ and 317 according to the obtained results a substance 4 is Trans/cis resveratrol MW 228; a substance $5 \mathrm{~m} / \mathrm{z} 453$, [M-H]-, fragment $\mathrm{m} / \mathrm{z} 107[\mathrm{M}-\mathrm{H}]-\Lambda \max 306$ according to the obtained results a substance 5 is $\varepsilon$-Viniferin MW 454.

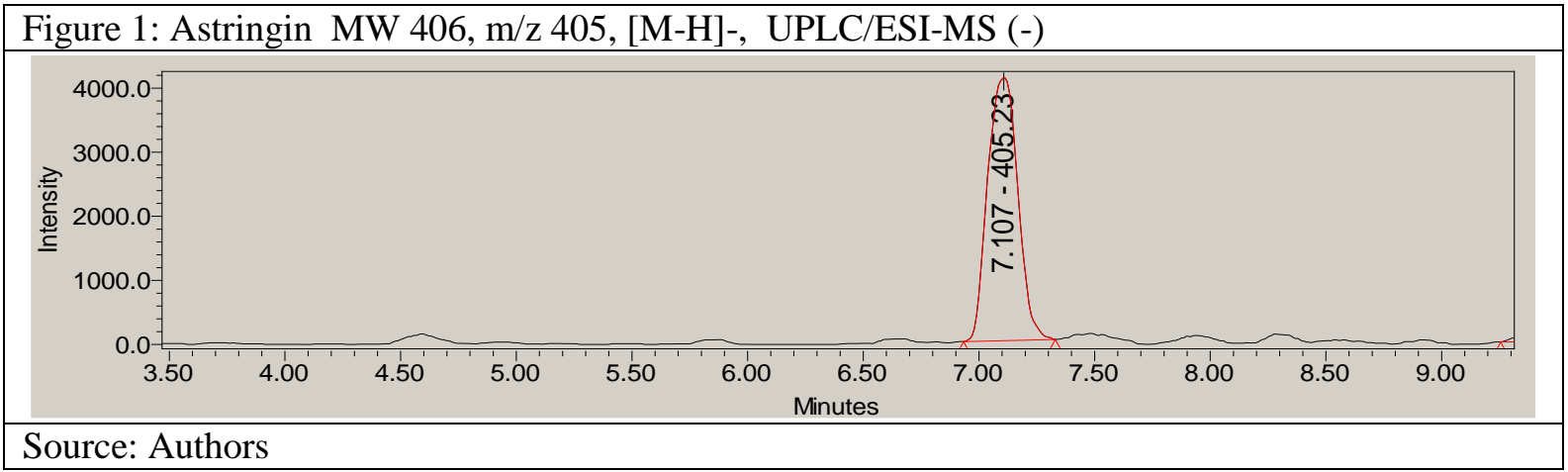

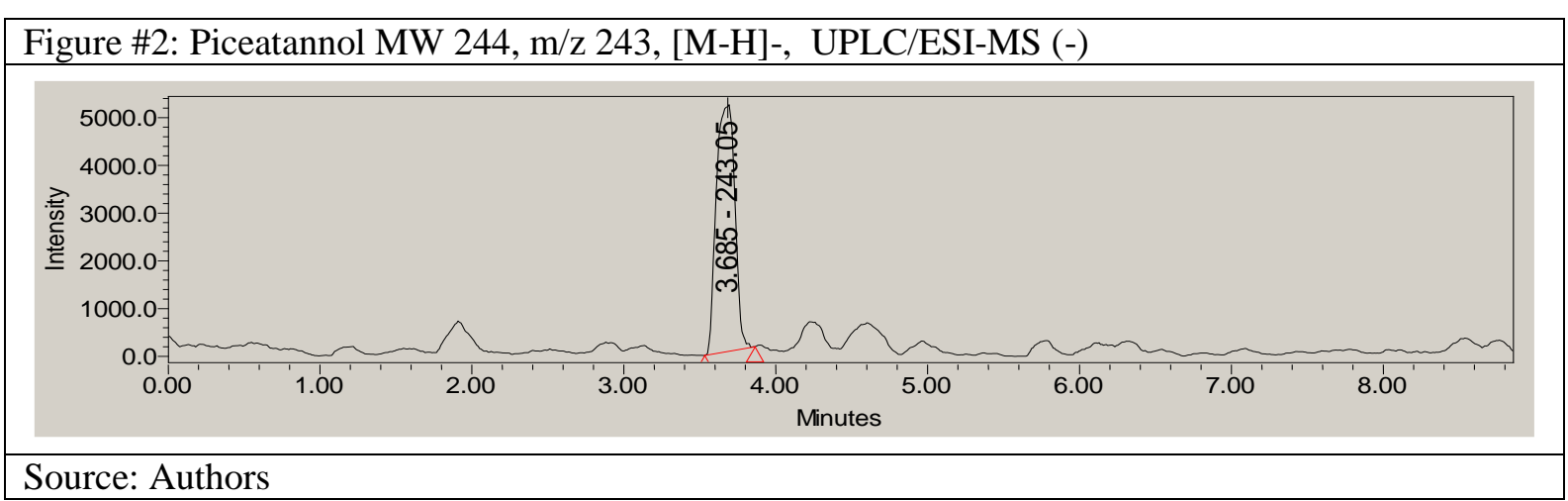



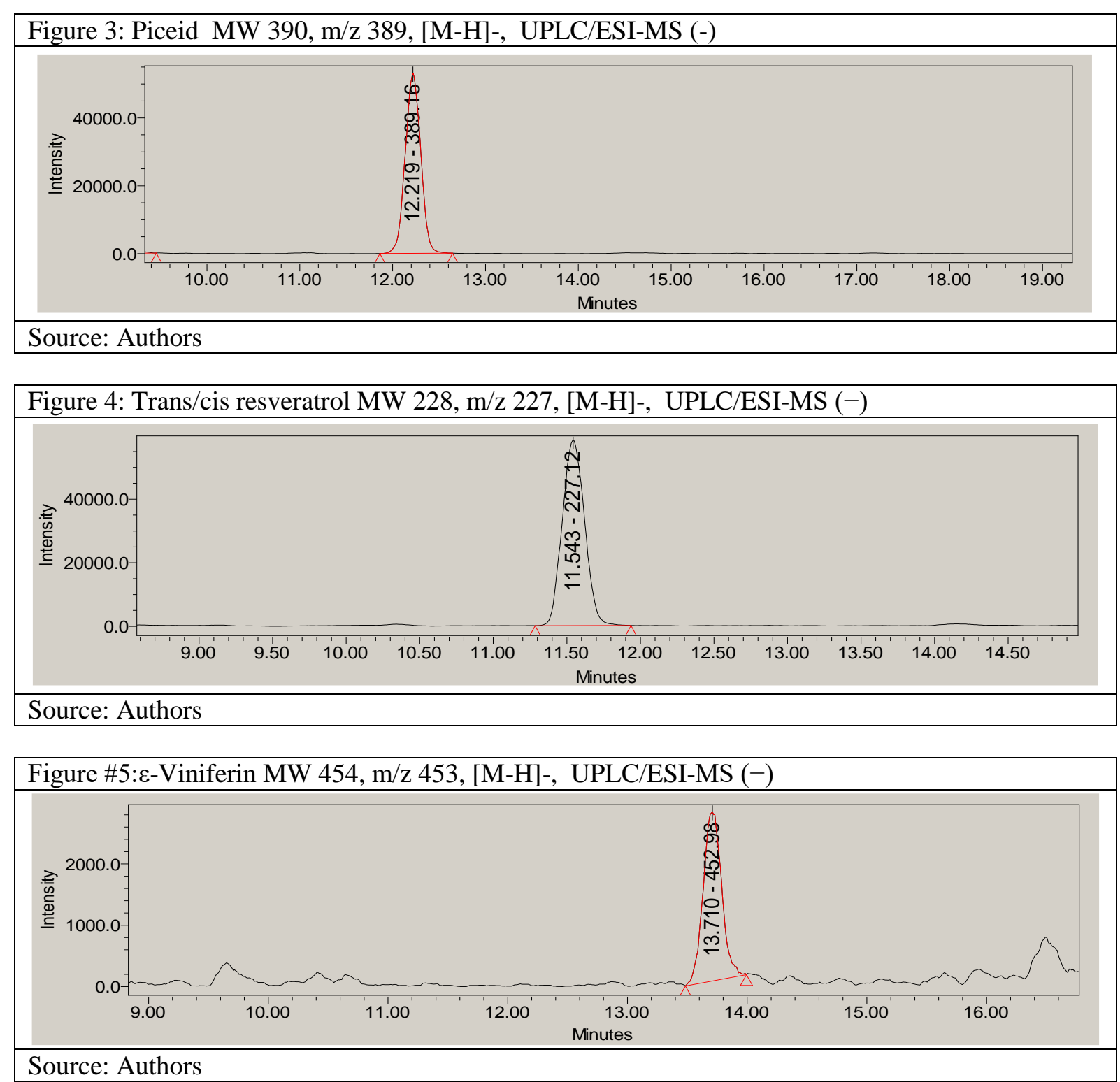

\begin{tabular}{l} 
Table 1: MS characterization of wine stilbenes \\
\begin{tabular}{|l|l|l|l|l|l|l|l|l|}
\hline$\#$ & Compounds Stilbenes & MW & M/Z + & Fragm & M/Z - & Fragm & $\kappa$ max & Sample \\
\hline 1 & Astringin & 406 & 407 & 196 & 405 & & 307 & Red Wine \\
\hline 2 & Piceatannol & 244 & 245 & 135 & 243 & & 306,322 & Grapevine \\
\hline 3 & Piceid & 390 & 391 & 229 & 389 & 227 & 308,319 & Grapevine \\
\hline 4 & Trans/cis resveratrol & 228 & 229 & 107 & 227 & 185 & 306,317 & Red Wine \\
\hline 5 & $\varepsilon$-Viniferin & 454 & 455 & 107 & 453 & & 306 & Grapevine \\
\hline
\end{tabular} \\
\hline
\end{tabular}

\begin{tabular}{|l|r|r|r|r|r|r|}
\hline Table \#2: Stilbenes $\mathrm{mg} \mathrm{kg}^{-1}$ in grapes (expressed as trans-resveratrol) \\
\hline Wine Name & Piceid & Trans/cis resveratrol & Astringin & $\varepsilon$-Viniferin & $\begin{array}{c}\text { Total } \\
\text { stilbenes }\end{array}$ & $\begin{array}{c}\text { Antioxidant activity } \\
\text { (AA) }\end{array}$ \\
\hline Aleqsandrouli & 67.4 & 50.14 & 17.8 & 14.2 & 148.82 & 19.80 \\
\hline Mujuretuli & 89.9 & 102.3 & 23.1 & 20.24 & 215.30 & 17.10 \\
\hline Aladasturi & 75.74 & 22.15 & 9.9 & 24.2 & 131.99 & 18.81 \\
\hline Chkhaveri & 86.25 & 10.61 & 3.13 & 7.51 & 77.50 & 20.14 \\
\hline Ojaleshi & 98.9 & 124.6 & 6.61 & 30.6 & 260.71 & 7.36 \\
\hline
\end{tabular}

Source: Authors 
It is noteworthy that in the analyzed grape fruit and wine obtained from 5 red grape varieties (the Aleqsandrouli, the Mujuretuli, the Aladasturi, the Chkhaveri, the Ojaleshi), we have identified that the dominant compound is Trans/cis resveratrol and Piceid, which together make up more than $90 \%$ of the total content of Stilbenes.

Stilbenes are unevenly distributed in different grape varieties and, correspondingly, in the wine produced from them. Among the studied varieties, the highest total maximum amount of Stilbenes is in the Ojaleshi and the Mujuretuli samples (the total content is 260.71 and $215.3 \mathrm{mg} \mathrm{kg}^{-1}$ respectively). $50 \%$ of the total content belong to Resveratrol. Relatively fewer stilbenes are in the Alexandrouli (148.82 mg $\left.\mathrm{kg}^{-}{ }^{1}\right)$ and the Aladasturi (131.99 $\left.\mathrm{mg} \mathrm{kg-}^{1}\right)$, however, these samples are distinguished by the maximum content of Piceid in the total amount $\left(67.4 \mathrm{mg} \mathrm{kg}^{-1}, 75.74 \mathrm{mg} \mathrm{kg-}^{-1}\right)$. The lowest number of Stilbenes is presented in the Chkhaveri $\left(77.5 \mathrm{mg} \mathrm{kg}^{-1}\right)$. The content of Stilbenes decreases by a certain proportion in the following wines: Aladasturi-19.17 mgkg- ${ }^{1}$, Aleksandrouli $14.87 \mathrm{mgkg}^{1}{ }^{1}$, Mujuretuli $21.36 \mathrm{mgkg}^{1}$, Chkhaveri $14.5 \mathrm{mgkg}^{-}{ }^{1}$, Ojaleshi $60.8 \mathrm{mgkg}^{-1}$.

A direct proportionate relationship between the total composition and the antioxidant activity of Stilbenes has also been determined. In this respect, the Ojaleshi and the Mujuretuli wines have the highest rates $(0.1 \mathrm{mM}$ DPPH $50 \%$ inhibition from $7.36 \mathrm{~mL}$ and $17.1 \mathrm{mg}$ respectively), while the Chkhaveri has a relatively low rate $(20.14 \mathrm{mg})$. Moreover, there is a direct connection between the amount of stilbenes and the antioxidant properties of the sample. The higher the total stilbene amount the lower the amount of grape juice and wine is needed to inhibit $0.1 \mathrm{mM}$ DPPH $50 \%$ which means that the antioxidant property is high. A similar relationship can also be observed with other types of grapes.

\section{Conclusion}

The Georgian Autochthonous red grape varieties of Aleqsandrouli, Mujuretuli, Aladasturi, Chkhaveri, and Ojaleshi and the red wines obtained from them are distinguished by their content of Stilbenestrans/cis resveratrol, Piceid, Astringin, $\varepsilon$-Viniferin. Among the wines, produced from the above grape varieties, the highest content of Stilbenes is in the varieties of Ojaleshi and Mujuretuli.

A correlation was found between the total content of Stilbenes and antioxidant activity. The amount of stilbenes in the Georgian Autochthonous grapes and wines is directly coorelated with the antioxidant activity

\section{Acknowledgment}

The designated Project was fulfilled through the financial support of the Georgia National Science Foundation (Grant AP/96/13, Grant216816). Any idea in this publication is possessed by the author and may not represent the opinion of the Georgia National Science Foundation.

\section{References}

Alonso-Villaverde, V., Voinesco, F., Viret, O., Spring, J., \& Gindro, K. (2011). The effectiveness of stilbenes in resistant Vitaceae: Ultrastructural and biochemical events during Plasmopara viticola infection process. Plant Physiology and Biochemistry,49(3), 265-274. doi:10.1016/j.plaphy.2010.12.010

Anastasiadi, M., Pratsinis, H., Kletsas, D., Skaltsounis, A., \& Haroutounian, S. A. (2010). Bioactive non-coloured polyphenols content of grapes, wines and vinification by-products: Evaluation of the antioxidant activities of their extracts. Food Research International,43(3), 805-813. doi:10.1016/j.foodres.2009.11.017

Careri, M., Corradini, C., Elviri, L., Nicoletti, I., \& Zagnoni, I. (2003). Direct HPLC Analysis of Quercetin andtransResveratrol in Red Wine, Grape, and Winemaking Byproducts. Journal of Agricultural and Food Chemistry,51(18), 52265231. doi:10.1021/jf034149g

Decendit, A. (2017). Identification and quantification of stilbenes in some Tunisian red wines using UPLC-MS and HPLCDAD. OENO One,51(2). doi:10.20870/oeno-one.2017.51.2.1673

Gülçin, I. (2010). Antioxidant properties of resveratrol: A structure-activity insight. Innovative Food Science \& Emerging Technologies, 11(1), 210-218. doi:10.1016/j.ifset.2009.07.002

Hao, H. D., \& He, L. R. (2004). Mechanisms of Cardiovascular Protection by Resveratrol. Journal of Medicinal Food,7(3), 290-298. doi:10.1089/jmf.2004.7.290

Hurtado-Gaitán, E., Sellés-Marchart, S., Martínez-Márquez, A., Samper-Herrero, A., \& Bru-Martínez, R. (2017). A Focused Multiple Reaction Monitoring (MRM) Quantitative Method for Bioactive Grapevine Stilbenes by Ultra-High-Performance Liquid Chromatography Coupled to Triple-Quadrupole Mass Spectrometry (UHPLC-QqQ). Molecules, 22(3), 418. doi:10.3390/molecules22030418

Ji, M., Li, Q., Ji, H., \& Lou, H. (2014). Investigation of the distribution and season regularity of resveratrol in Vitis amurensis via HPLC-DAD-MS/MS. Food Chemistry, 142, 61-65. doi:10.1016/j.foodchem.2013.06.131 
López-Hernández, J., \& Quirós, A. R. (2016). Trans-Stilbenes in Commercial Grape Juices: Quantification Using HPLC Approaches. International Journal of Molecular Sciences, 17(10), 1769. doi:10.3390/ijms17101769

Marel, A., Lizard, G., Izard, J., Latruffe, N., \& Delmas, D. (2008). Inhibitory effects oftrans-resveratrol analogs molecules on the proliferation and the cell cycle progression of human colon tumoral cells. Molecular Nutrition \& Food Research,52(5), 538-548. doi:10.1002/mnfr.200700185

Rimando, A. M., Kalt, W., Magee, J. B., Dewey, J., \& Ballington, J. R. (2004). Resveratrol, Pterostilbene, and Piceatannol inVacciniumBerries. Journal of Agricultural and Food Chemistry,52(15), 4713-4719. doi:10.1021/jf040095e

Sánchez, J. J., Corral, E. C., Delgado, M. S., Orea, J., \& Ureña, A. G. (2005). Analysis of trans-resveratrol by laser ionization mass spectrometry and HPLC with fluorescence detection. Journal of Chromatography A,1074(1-2), 133-138. doi:10.1016/j.chroma.2005.03.093

Shen, T., Wang, X., \& Lou, H. (2009). Natural stilbenes: An overview. Natural Product Reports,26(7), 916. doi:10.1039/b905960a

Tang, G., Zhao, C., Liu, Q., Feng, X., Xu, X., Cao, S.,Li, H. (2018). Potential of Grape Wastes as a Natural Source of Bioactive Compounds. Molecules, 23(10), 2598. doi:10.3390/molecules23102598

Wen, H., Fu, Z., Wei, Y., Zhang, X., Ma, L., Gu, L., \& Li, J. (2018). Antioxidant Activity and Neuroprotective Activity of Stilbenoids in Rat Primary Cortex Neurons via the PI3K/Akt Signalling Pathway. Molecules, 23(9), 2328. doi:10.3390/molecules23092328 